\title{
С.Б. Авдашева
}

Департамент прикладной экономики ФЭН Национального исследовательского университета «Высшая школа экономики», Москва

\section{Теория конкуренции - экономической политике}

Аннотация. В России сформировалась традиция применять для оценки реформ монетарной и налоговой политики современные методы макроэкономического анализа, а для оценки реформ на микроуровне - методы институционального анализа. Методы микроэкономического анализа при планировании реформ до сих пор применяются редко, хотя влияние преобразований на стимулы участников рынков может быть существенным. В статье приведены три примера проводимых и планируемых реформ, для оценки которых может быть полезен микроэкономический анализ: предписания о ценах в отношении крупных экспортеров, варианты реформы тарифного регулирования и моделей государственных закупок, либерализация внутреннего рынка газа. В первом и третьем случае правила, нацеленные на поддержку покупателей и стимулирование конкуренции, могут парадоксально повышать стимулы к неконкурентному поведению. Во втором случае стремление регламентировать способы закупок с предпочтениями в пользу более конкретных форм способно подавить стимулы к повышению производительности использования ресурсов, лежащие в основе конкуренции.

Ключевые слова: микроэкономика, предписания о иенах, реформа тарифного регулирования и закупок, либерализаиия внутреннего рынка газа.

Классификация JEL: L12, L40, L51.

\section{1. Введение}

Микроэкономический анализ как инструмент обсуждения проблем экономической политики в России применяется редко. В качестве аналитического инструмента он все больше проигрывает макроэкономике и институциональной әкономике. В принципе это можно объяснить двумя обстоятельствами - аналитическим охватом и соотношением в моделях наблюдаемых и ненаблюдаемых переменных. Предмет микроэкономической модели сложно сопоставить с предметом макроэкономической теории, объясняющей экономическую активность в масштабе страны. Точно так же сложно соперничать с институциональным анализом, претендующим на всеобъемлющее объяснение явлений и процессов. Микроэкономика ограничена набором предпосылок, отражающих условия взаимодействия здесь и сейчас, в контексте конкретных рынков. Вдобавок микроэкономике на протяжении последних 50 лет привычно включать в модели ненаблюдаемые переменные и пытаться объяснять результаты взаимодействия в условиях, когда

не только внешний наблюдатель, но и собственно участники взаимодействия не обладают полной информацией о характеристиках своих контрагентов. Эти два обстоятельства делают микроэкономический инструмент анализа, по общему мнению, слишком трудоемким для решения тех задач, которые ему по силам.

Однако забвение (или неознакомление) с базовыми микроэкономическими моделями ограничивает интеллектуальный потенциал и в конечном итоге может привести к исчезновению существенных эффектов реформ из поля зрения исследователя. Такая опасность значительна для преобразований, которые затрагивают стимулы продавцов конкурировать друг с другом.

Цель статьи - продемонстрировать те выводы микроэкономических моделей, которые могут быть полезными при планировании отдельных реформ, затрагивающих конкретные рынки. В число задач не входят ни обсуждение, ни критика альтернативных концепций реформ, ни обоснование собственных пред-

\footnotetext{
${ }^{1}$ В статье использованы результаты проекта, выполненного в рамках Программы фундаментальных исследований Национального исследовательского университета «Высшая школа экономики» в 2017 г.
} 
ложений. Любая реформа создает множество эффектов, одна из первых задач реформатора - провести их инвентаризацию. В статье рассмотрены три примера проходящих в России реформ: предписания о ценах в отношении крупных әкспортеров, альтернативные модели тарифного регулирования и закупок и действия по либерализации внутреннего рынка газа. Инструменты каждой из этих реформ воздействуют на стимулы участников рынка прилагать усилия для снижения затрат, привлекать и расходовать деньги на инвестиции, конкурировать за покупателей.

\section{2. Предписания о ценах для} предотвращения ценовой дискриминации отечественных продавцов

Ценовые предписания в отношении крупных отечественных әкспортеров появились в ответ на проблему ценовой дискриминации третьей степени на рынках экспортной продукции. Существует тенденция назначения крупными российскими экспортерами цен на внутреннем рынке выше, чем их собственные цены экспортных поставок (Голованова, 2010). Альтернативные методы решения этой проблемы продемонстрировали меньшую результативность, чем ценовые предписания (Авдашева, Корнеева, 2016).

$\mathrm{C}$ точки зрения соответствия критерию общественного благосостояния задача ФАС России предотвращения ценовой дискриминации третьей степени вполне оправдана. Еще Джоан Робинсон показала (Robinson, 1933), что эта модель ценовой дискриминации сопровождается повышением благосостояния только в том случае, если она ведет к повышению суммарного объема продаж. Имеется в виду суммарное благосостояние в разрезе обоих рынков - применительно к нашему случаю, российского и мирового рынка продуктов. Для внутреннего рынка әкспортеров сложно предложить набор таких предпосылок, при выполнении которых более высокая цена на российском рынке по сравнению с миро- вым сопровождается ростом благосостояния, если на мировом рынке цена обеспечивает прибыль ${ }^{2}$.

Несмотря на оправданность задачи, практика предписаний в виде торговых или маркетинговых политик была и остается объектом критики (Радченко, Шаститко, 2013; Авдашева, 2013). Критика адресована усилению мотивов регулирования в принятии коммерческих решений компаниями, соответствующему ограничению мотивов маркетинга и менеджмента. Однако есть по крайней мере один аспект, на который мало обращали внимание российские комментаторы ценовых предписаний, но который важен в сравнении с другими возможными эффектами реформ. Влияние предписаний на ценовую конкуренцию на мировых рынках, где российские экспортеры имеют значительную долю. В первую очередь речь идет о сырье.

Большинство мировых рынков сырья относятся к рынкам несовершенной конкуренции, где возможна как конкуренция, так и поддержание высоких цен. Выбирая между поддержанием высоких цен и их снижением, продавцы сопоставляют выигрыши при двух вариантах поведения (Ivaldi et al., 2003). Рассмотрим модификацию стандартной постановки народной теоремы. Напомним ее содержание: если участники некооперативного взаимодействия достаточно высоко оценивают будущие выигрыши, в бесконечно повторяющейся игре могут поддерживаться любые стратегии, приносящие выигрыши, превышающие выигрыши при однократном взаимодействии (Friedman, 1971). Пусть неконкурентное поведение сопровождается разделом рынка (аналогично модели (Bhattacharjea, Sinha, 2015)) при наличии издержек торговли. Пусть $A$ и $B-$ «рынок домашний» и «рынок конкурентов», $\pi^{M}$ - прибыль при монополии (отражающей любое неконкурентное поведение), $\pi^{D}-$ прибыль при отклонении от цены монополии (что соответствует ценовой конкуренции; в модели раздела рынка эту прибыль можно

\footnotetext{
2 Среди таких предпосылок - продажа связанных в производстве товаров (Шаститко, Шаститко, 2015). Несмотря на то что производство большинства российских экспортеров диверсифицировано, можно ожидать, что эффект связанного в производстве товара будет очень сильно влиять на издержки немногих из них.
} 
получить только на «рынке конкурентов»), $\pi^{P}$ - прибыль монополиста после реакции конкурентов на его понижение цены; $\delta$ - дисконтирующий множитель. Чем ниже значение дисконтирующего множителя, при котором выполняется условие

$$
\frac{\pi_{A}^{M}}{1-\delta}=\pi_{A}^{M}+\pi_{B}^{D}+\frac{\delta \pi_{A}^{P}}{1-\delta},
$$

тем слабее стимулы ценовой конкуренции.

Пусть предписанием на внутреннем рынке (рынок $A$ ) установлена верхняя граница цены, равная разности между ценой «рынка конкурентов» и издержками торговли. В этом случае $\pi_{A}^{P}$ выше при отсутствии предписаний, ограничивающих цену на внутреннем рынке. Насколько бы конкуренты ни понизили цену в ответ на понижение цены рассматриваемым продавцом, цена внутреннего рынка и прибыль на нем после введения предписаний окажется ниже. Значение дисконтирующего множителя, обеспечивающего выполнение условия (1), ниже, иначе говоря, стимулы неконкурентного поведения на внешнем для продавца рынке выше.

Правда, даже если предписания действительно усиливают стимулы поддерживать высокие цены, это еще не указывает на невыполнение задач ФАС России. Пусть снижение цен внутреннего рынка относительно мировых цен сопровождается растущими ценами мирового рынка (в относительном выражении, по сравнению с возможными ценами при отсутствии искажений стимулов продавцов). Задача поддержания отечественных производителей на следующем этапе цепочки создания стоимости все равно решается, поскольку на их ценовую конкурентоспособность положительно влияет снижение относительных цен сырья на внутреннем рынке. Показатель общественного благосостояния на домашнем рынке может повышаться благодаря двум әффектам: 1) росту прибыли российских әкспортеров сырья из-за ослабления ценовой конкуренции; 2) росту прибыли перерабатывающего сегмента в результате снижения относительных цен на сырье. Для национальной экономики комбинация ослабления конкуренции на внешних сырьевых рынках и предписаний на вну- тренних рынках может оказаться благоприятной по сравнению с отсутствием предписаний. Однако влияние национальных предписаний на конкуренцию на мировом рынке - сам по себе важный предмет анализа.

\section{3. В поисках лучшей модели тарифного регулирования и закупок}

Преобразования моделей тарифного регулирования и государственных закупок, начавшиеся более 20 лет назад, далеки от завершения. На это указывают и результаты частных исследований вариантов моделей регулирования тарифов на тепло и передачу электроэнергии (Гимади, 2016; Орлова, Кадрева, 2016). Сохраняется неудовлетворенность распорядителей бюджета и экспертов и результатами государственных закупок: до сих пор хорошим считается результат, когда распорядителям государственного бюджета удается в результате конкурса приобрести товар ненамного дороже, чем его можно было получить без конкурса, в магазине или на бензоколонке (Яковлев и др., 2013; Яковлев и др., 2014; Бальсевич, Подколзина, 2014). При этом в основу российской политики тарифного регулирования и государственных закупок положены принципиально различные подходы. Так, разрабатываемая реформа тарифного регулирования (по состоянию на весну 2017 г.) предполагает пять альтернативных моделей с разной зависимостью тарифа от издержек регулируемой компании. На одном конце спектра - тариф на базе обоснованных расходов конкретного продавца, на другом - на уровне эталонных, определенных исходя из расходов другого поставщика с нормальной производительностью. Между этими двумя крайними моделями - тариф на основе доходности инвестированного капитала, индексации и сопоставимых цен. Целесообразность применения различных моделей регулирования тарифов полностью соответствует выводу микроэкономического анализа установления цены единственным покупателем в условиях неполноты информации, метод, который считается центральным в работах лауреата Нобелевской премии 2014 г. Жана Тироля (Авдашева, Шаститко, 
2015; Tirole, 2014). Применение тарифов, не основанных на издержках, делает для компаний выгодным повышение әффективности использования ресурсов и соответствующую ей экономию затрат. Однако стимулирование таким способом компаний с высокими затратами требует назначения слишком высоких цен, существенно снижающих выигрыш покупателя по сравнению с ценой, компенсирующей затраты. Вот почему оптимальная система регулирования тарифов предполагает зависимость правил назначения цены от уровня издержек: не зависящие от издержек цены стимулируют более успешных продавцов повышать производительность, компенсация издержек поддерживает возможность выпускать продукцию менее успешным продавцам. Самая важная характеристика такой модели тарифного регулирования - зависимость способов назначения тарифов от особенностей конкретного продавца, от соотношения его производительности с производительностью лучших и средних продавцов отрасли, от способности продавца повысить производительность благодаря своим усилиям, а также от рисков изменения спроса и цен ресурсов, с которыми сталкиваются продавцы.

Модель оптимального назначения регулируемых цен Лаффона-Тироля обосновывает два направления экономической политики: собственно тарифное регулирование и государственные закупки. Вывод о применении вариативных методов определения поставщика и назначения цены в полной мере относится к закупкам, как и к тарифному регулированию. Однако в сфере государственных закупок и закупок регулируемых компаний российская конкурентная политика следует в противоположном направлении - максимального упрощения и унификации правил. При разнообразии предметов и условий закупок такая стратегия экономической политики сопровождается значительными потерями у закупающих и поставщиков (Авдашева и др., 2013). Стремление стандартизировать правила закупок объясняется опасением, что дискреционные решения распорядителей бюджета будут сопровождаться коррупцией.
Однако в предлагаемой модели тарифного регулирования предусмотрен не меньший уровень дискреции, в то время как неоднородность производимых товаров и услуг здесь даже ниже, чем в государственных закупках, и тем более в закупках регулируемых компаний. Сопоставление характеристик этих сфер регулирования может быть полезным с учетом выводов микроэкономики об оптимальном механизме назначения цен в условиях неполноты информации и неоднородности поставщиков.

\section{4. Либерализации цен на внутреннем рынке газа}

Принципы либерализации внутреннего рынка газа - вопрос, не сходящий с повестки дня. Среди измерений правил либерализации - отказ от тарифного регулирования в части установления нижней границы цены крупнейшего российского поставщика газа ПАО «Газпром» (Гордеев и др., 2015). По умолчанию предполагается, что способность крупнейшего продавца снижать цены должна сопровождаться усилением ценовой конкуренции. Микроэкономика не дает оснований для безоговорочного оптимизма по этому вопросу. Способность крупных продавцов снижать цены может сопровождаться прямо противоположным результатом. Обратимся к условию (1). Оно показывает, что стимулы поддерживать высокую цену (в более общей формулировке - отказаться от ценовой конкуренции) тем выше, чем большее снижение цены со стороны других продавцов может последовать в качестве ответной реакции. В этом контексте способность крупнейшего продавца радикально снизить цену может быть фактором, удерживающим других участников от активной ценовой конкуренции.

На возможность парадоксальных последствий либерализации цен указывает не только модель народной теоремы, но и опыт реформирования регулируемых рынков. Вспомним реформу электроэнергетики в Калифорнии. Самый радикальный шаг в сторону конкуренции: запрет долгосрочных контрактов между генераторами и розничными 
поставщиками, установление оптовых цен на бирже - привел к резкому повышению цен. По некоторым оценкам, подавляющая часть этого повышения цен объясняется исключительно стратегическим взаимодействием между поставщиками электроэнергии (Joskow, 2001). Опыт Калифорнии показывает, что стимулы снижения цен - не то же самое, что возможности снижения. Стратегическое взаимодействие продавцов точнее объясняет их ценовые решения, чем уровень издержек.

\section{5. Заключение}

Во всех рассмотренных примерах модели микроэкономики демонстрируют три возможности. Они позволяют разделить и сопоставить два типа изменений поведения участников рынка. Первый тип - изменения, которые предполагает реформатор. Второй тип - изменения поведения, происходящие в результате решения задачи максимизации целевой функции (в приведенных примерах прибыли). Сопоставление этих изменений может привести к вполне ожидаемым для теоретиков результатам, но для реформаторов не всегда. Ограничение цены определенной планкой сверху может привести не только к снижению цены, но и к повышению уровня самой планки. Регулирование внутренних цен экспортируемых товаров на основании принципа равнодоходности не обязательно приведет к понижению внутренних цен; оно может привести и к повышению мировых цен. Верхняя планка регулируемых цен, отталкивающаяся от издержек на единицу продукции, может привести не к ограничению роста цен, а к росту издержек. Однако и разрыв цен с издержками не обязательно создаст стимулы снижать цены. Возможность крупных продавцов снижать цену на рынке олигополии не обязательно приводит к фактическому снижению цены. При определенных условиях они используют возможность противоположным образом - для поддержания стабильно высокой цены.

Кроме того, модели заставляют задуматься о зависимости моделей поведения участников рынка, и как следствие резуль- татов изменения правил, от характеристик структуры рынка. Среди важнейших выводов современного микроэкономического анализа - важность особенностей организации конкретного рынка, на котором происходят те или иные изменения. Буквально одна и та же реформа может противоречиво влиять на поведение, диктуемое мотивами максимизации прибыли, и приводить к разным результатам при различной рыночной структуре. Микроэкономический анализ очень чувствителен к предпосылкам. Адекватное прогнозирование исхода преобразований требует тщательной проверки соответствия используемых в модели предпосылок фактической структуре рынков и секторов, которые являются объектом преобразований.

Более того, высокая требовательность к предпосылкам заставляет при планировании реформ более тщательно исследовать организацию конкретных российских рынков, включая факторы формирования издержек, зависимость издержек от выпуска, соотношение издержек и мощностей разных групп продавцов, политику в отношении разных целевых рынков и факторов формирования прибыли. Тем самым использование предельно, казалось бы, абстрактных моделей делает насущной необходимостью конкретные знания об отраслях и рынках.

\section{ЛИТЕРАТУРА}

Авдашева С.Б. (2013). Влияние регуляторной среды на модель корпоративного управления компаний с государственным участием: проблемы современной России / / Журнал Новой экономической ассочиа иии. № 20 (4). С. 159-164.

Авдашева С.Б., Корнеева Д.В. (2016). Конкурентная политика на экспортоориентированных рынках: действительно ли компенсирующие меры әффективны? // Экономический журнал Высшей школь экономики. № 20 (3). С. 442-470.

Авдашева С.Б., Шаститко А.Е. (2015). Нобелевская премия по экономике - 2014: Жан Тироль / / Вопросъ экономики. № 1. C. 5-21. 
Авдашева С.Б., Крючкова П.В., Горейко Н.А., Захаров О., Круглова Е., Галашин С. (2013). Законодательная регламентация закупок регулируемых компаний и компаний госсектора: экономические эффекты правовых новаций. М.: МАКС Пресс.

Бальсевич А.А., Подколзина Е.А. (2014). Причины и последствия низкой конкуренции в государственных закупках в России // Экономический журнал Высшей школы экономики. № 18 (4). С. 563-585.

Гимади В.И. (2016). Влияние методов тарифного регулирования в теплоснабжении на решение потенциального инвестора // Вестник МГУ. Серия 6 «Экономика». № 5. С. 92-112.

Голованова С.В. (2010). Сигналы несовершенства конкуренции: результаты анализа цен товаров, вовлеченных в международную торговлю // Современная конкурениия. № 4. С. 11-25.

Гордеев Д., Идрисов Г., Карпель Е. (2015). Теоретические и практические аспекты ценообразования на природный газ на внутреннем и внешнем рынках // Boпросы экономики. № 1. С. 80-102.

Орлова Ю.А., Кадрева О.Н. (2016). Влияние стимулирующего регулирования тарифов на инвестиции в электросетевом комплексе России // Вестник МГУ. Серия 6 «Экономика». № 5. С. 69-91.

Радченко Т., Шаститко А. (2013). Регламентация торговой политики частной компании: теория, практика и выводы для антитраста // Экономическая политика. № 5. С. $81-105$.

Шаститко А., Шаститко А. (2015). Рынки связанных по производству товаров: теоретическая модель и уроки для правоприменения // Вопросы экономики. № 2. C. 5-21.

Яковлев А.А., Башина А.С., Демидова О.А. (2013). Анализ әффективности различных способов закупки простого однородного товара (на примере сахарного песка) / / Экономический журнал Высшей школъ экономики. № 17 (4). С. 617-645.
Яковлев А.А., Выгловский О.В., Демидова О.А., Башлык А.Н. (2014). Добросовестное и недобросовестное поведение в повторяющихся закупках: эмпирический анализ // Экономический журнал Высшей школь экономики. № 18 (4). C. 538-562.

Bhattacharjea A., Sinha U.B. (2015). Multi-Market Collusion with Territorial Allocation / / International Journal of Industrial Organization. No. 41. P. 42-50.

Friedman J.W. (1971). A Non-Cooperative Equilibrium for Supergames // The Review of Economic Studies. Vol. 38 (1). P. 1-12.

Ivaldi M., Jullien B., Rey P., Seabright P., Tirole J. (2003). The Economics of Tacit Collusion. Final Report for DG competition, European Commission.

Joskow P.L. (2001). California's Electricity Crisis // Oxford Review of Economic Policy. Vol. 17 (3). P. 365-388.

Robinson J. (1933). The Economics of Imperfect Competition. London: Macmillan.

Tirole J. (2014). Market Power and Regulation. In: "Scientific Background on the Sveriges Riksbank Prize in Economic Sciences in Memory of Alfred Nobel".

Поступила в редакиию 20 июня 2017 года

REFERENCES (with English translation or transliteration)

Avdasheva S. (2013). Impact of Regulatory Constraints on Corporate Governance in the Contemporary Russian SOE. Journal of the New Economic Association, 20 (4), 159-164 (in Russian).

Avdasheva S., Korneeva D. (2016). Competition Policy in Export-Oriented Markets: Whether Remedies Are Really Effective? Higher School of Economics Economic Journal, 20 (3), 442-470 (in Russian).

Avdasheva S., Kryuchkova P., Goreiko N., Zakharov O., Kruglova E., Galashin S. (2013). Legal Rules on Procurement of Regulated Companies and SOEs. Moscow: Maks Press (in Russian). 
Avdasheva S., Shastitko A. (2015). Nobel Memorial Prize in Economics - 2014: Jean Tirole. Vorposy Ekonomiki, 1, 5-21 (in Russian).

Balsevitch A., Pogkolzina E. (2014). Causes and Consequences of Low Competition in Russian Public Procurement. Higher School of Economics Economic Journal, 18 (4), 563-585 (in Russian).

Bhattacharjea A., Sinha U.B. (2015). Multi-Market Collusion with Territorial Allocation. International Journal of Industrial Organization, 41, 42-50.

Gimadi V. (2016). Impact of Tariff Regulation on Investment Decision in District Heating. Moscow University Herald, Serie 6 'Economics', 5, 92-112 (in Russian).

Golovanova S. (2010) Evidence on Imperfect Competition: Prices of Exported and Imported goods in Russia. Modern Competition Journal, 4, 11-25 (in Russian).

Gordeev D., Idrisov G., Karpel E. (2015). Theory and Practice for Natural Gas Pricing in Russia. Voprosi Ekonomiki, 1, 80-102 (in Russian).

Friedman J.W. (1971). A Non-Cooperative Equilibrium for Supergames. The Review of Economic Studies, 38 (1), 1-12.

Ivaldi M., Jullien B., Rey P., Seabright P., Tirole J. (2003). The Economics of Tacit Collusion. Final report for DG competition, European Commission.

Joskow P.L. (2001). California's Electricity Crisis. Oxford Review of Economic Policy, 17 (3), 365-388.
Orlova Ju., Kadreva O. (2016). Impact of Tariff Regulation on Investments in Russian Electricity Distribution Sector. Moscow University Herald, Series 6 'Economics', 5, 69-91 (in Russian).

Radchenko T., Shastitko A. (2013). Regulations of Private Companies' Trade Policies: Theory, Practice and Recommendations for Antitrust. Economic Policy, 5, 81-105 (in Russian).

Robinson J. (1933). The Economics of Imperfect Competition. London: Macmillan.

Shastitko A., Shastitko A. (2015). Markets of Joint Products: Theoretical Model and Policy Implications. Voprosy Ekonomiki, 2, 5-21 (in Russian).

Tirole J. (2014). Market Power and Regulation. In: "Scientific Background on the Sveriges Riksbank Prize in Economic Sciences in Memory of Alfred Nobel".

Yakovlev A., Bashina A., Demidova O. (2013). Efficiency of Simple Homogeneous Good Procurement under Rigid Governmental Regulation: The Case of Sugar Sand Procurement in Russia. Higher School of Economics Economic Journal, 17 (4), 617-645.

Yakovlev A., Vyglovkiy O., Demidova O., Bashlyk A. (2014). Honest and Opportunistic Incentives in Repeated Procurements: Empirical Analysis. Higher School of Econom ics Economic Journal, 18 (4), 538-562 (in Russian).

Received 20.06.2017

\section{S.B. Avdasheva}

Applied Economics Department, Faculty of Economic Sciences National Research University Higher School of Economics, Moscow, Russia

\section{Theory of Competition for Economic Policy}

Abstract. In Russia, there is already strong tradition to apply macroeconomic models and institutional analysis in order to assess the effects of recent and prospective reforms. One rarely applies microeconomic models for this objective, in spite of the fact that impact of prospective reforms on the incentives of market participants might be substantial. An article lists three examples of economic policy issues, where microeconomic analysis might explain important effects of reforms. These are price remedies for large exporting companies, alternative methods of tariff regulation and models of procurement, and liberalization of domestic natural gas market. In the first and the third case the rules that were designed to enhance consumer benefits and promote competition, paradoxically can support anticompetitive market strategies. In the second case, the intention to narrow the rules of procurement in favor of more competitive ones, is able to suppress the incentives to increase productivity that is the basis for competition.

Keywords: microeconomics, price remedies, tariff regulation, public procurement, liberalization of domestic gas market.

JEL Classification: L12, L40, L51. 